\title{
Prioritizing Pregnant Women's Preferences to Receive Health Information Before and During Pregnancy in Semnan in 2014 - 2015
}

\author{
Mehdi Kahouei, ${ }^{1}$ Mehri Ansari Niaki, ${ }^{2, *}$ Golnar Homayoon, ${ }^{3}$ and Somayeh Sadat Razavi ${ }^{3}$ \\ ${ }_{1}^{1}$ Research Center for Social Determinants of Health, Nursing and Allied Health School, Semnan University of Medical Sciences, Semnan, IR Iran \\ ${ }_{2}^{2}$ Maternal and Child Health Department, Nursing and Allied Health School, Semnan University of Medical Sciences, Semnan, IR Iran \\ ${ }^{3}$ Student Research Committee, Semnan University of Medical Sciences, Semnan, IR Iran \\ ${ }^{*}$ Corresponding author: Mehri Ansari Niaki, Maternal and Child Health Department, Nursing and Allied Health School, Semnan University of Medical Sciences, 5 Kilometers of \\ Damghan Road, P. O. Box:3513138111, Semnan, IR Iran. Tel:+98-2313354190, Fax:+98-2313354161, E-mail: ansariniaki@yahoo.com
}

Received 2015 October 30; Revised 2015 November 21; Accepted 2015 November 22.

\begin{abstract}
Background: Given that family health is tied to women health, illness, or death of a woman has an adverse effect on the health of her child, family, and community; awareness of women's preferences in receiving health information can help to improve and modify the methods of informing and providing appropriate services to them, and also makes pregnant women training more efficient and more effective.

Objectives: The aim of this study is to prioritize the preferences of women before and during pregnancy on receiving health information. Patients and Methods: This descriptive study was performed on pregnant women who had referred to health care centers affiliated to Semnan University of Medical Sciences, Iran in 2014. An anonymous self-administered questionnaire was developed.

Results: The results showed that $17.5 \%(n=35)$ of the participants reported their information needs about physical health to become pregnant, 36\% ( $n=72)$ psychological readiness for pregnancy and 57.5\% $(n=115)$ domestic violence and its impact on the health of the mother and fetus. Number of previous delivery had a negative and significant relationship with the pregnant women's preferences (B $=-1.31, \mathrm{P}<0.001)$

Conclusions: It is concluded that the most of pregnant women are oblivious to their health for getting pregnant and some of them experience symptoms of mental disorders in reproductive age. The findings show that domestic violence is a hidden and persistent epidemic among the pregnant women. Women, who had more previous delivery, needed this information less.
\end{abstract}

Keywords: Prioritizing, Pregnancy Women, Preferences, Health Information

\section{Background}

Today the world is an era that is called information era and the communities using them is called information communities (1). Information is vital and necessary for human, human in life to meet their needs require information, and information need originates from human life (2). Information needs are related to the needs that people should have them for doing tasks, solving issues and problems (3). In the present era, one of the important issues is information distribution, based on the actual need of the users. Information need causes the person using the information channels to seek information and express the behavior-based information (4). Women, as a part of the society, require to receive information at a desirable level. Types of information needs of women show their life quality position, and failure to meet information needs take away better life choice opportunity from them. Information receiving is essential, particularly for women because by entering pregnancy stage they start a high risk period that can have an uncomfortable end for them and the embryo with dangerous side effects (5).
With the advancement of medical sciences, the cause of most debilitating and deadly diseases, and complications in mothers and infants is known that the beginning of many of them returns to the time before pregnancy, i.e. when the diseases course and their complications can be stopped, or slowed by doing a series of health and medicine cares not to threaten fetal and maternal health (6).

A comprehensive program of cares related to pregnancy that includes medical, social, and psychological, must be started before pregnancy and continued until delivery (7). The purpose of these cares is identifying high-risk mothers, who are at risk of pregnancy in the future year to control mother metabolic diseases in the cares to be brought under control, and reduce their complications during pregnancy and provide a safe pregnancy and childbirth for the mother and baby (8). Preconception counseling and providing cares are more important than of providing pregnancy period cares because providing preconception cares leads to on time identifying and preventing risks that may arise for the baby or mother (9).

Copyright (C) 2016, Semnan University of Medical Sciences. This is an open-access article distributed under the terms of the Creative Commons Attribution-NonCommercial 4.0 International License (http://creativecommons.org/licenses/by-nc/4.0/) which permits copy and redistribute the material just in noncommercial usages, provided the original work is properly cited. 
Frey in a study done on 499 women, referred to outpatient services clinic, found that women information-level of preconception risk factors affecting on the outcome of pregnancy was good, and most of them preferred to receive information from their doctor and/or gynecologist (10).

During pregnancy period, many biological, chemical, physiological, and anatomical changes can happen in women's bodies. These changes are beyond their control, and these changes can made them vulnerable both physically and emotionally (11). In addition, occurrence of a series of discomforts is common during pregnancy period, such as nausea, vomiting, fatigue, varicose veins, etc. These changes can have significant effects on the daily activities of pregnant women (12). Lack of awareness and preparation during pregnancy period unknown fear lead to anxiety, complications and increasing day-to-day subsequent medical interventions, therefore attending classes of pregnancy period preparation and informing them can be a good solution to solve these problems among women (13). The results of the study of Moshki et al. on the lifestyle in Iranian pregnant women showed that it is necessary to educate and inform health care providers and pregnant women adequately in the field of using stress dealing techniques, and doing regular and correct physical activities (14).

Despite that women are expected to actively participate in decisions, related to providing health care during pregnancy (15), but studies have shown that some women in developing countries are often not allowed to go alone to health care institutions $(16,17)$. Given that family health is tied to women health, illness, or death of a woman has an adverse effect on the health of her child, family, and community (5).

Studies related to information needs of pregnant women are less concerned with pregnant women preferences prioritizing, and those studies did not clearly show that pregnant women prefer first, which information is provided. Awareness of women's preferences in receiving health information can help to improve and modify the methods of informing and providing appropriate services to them, and also makes pregnant women training more efficient and more effective.

\section{Objectives}

The aim of this study is to prioritize women's information needs before and during pregnancy on receiving health information.

\section{Patients and Methods}

\subsection{Subjects and Settings}

This descriptive study was performed on pregnant women who as outpatients had referred to Amiralmomenin hospital of Semnan University of Medical Sciences, Iran in 2014 -15. 200 pregnant women were estimated as samples based on similar studies $(7,10,13,18)$ and using the sample size estimation of Cochran (confidence level of 95\%).

\subsection{Data Gathering}

An anonymous self-administered questionnaire was developed. First, a 39-item survey was developed after reviewing gynecology literatures. It was divided into three areas: 1) demographics, such as age, job, education, location, gestational week, delivery times, count of abortion, gestational times, income level, consanguinity with spouse, spouse's job, and spouse's education; 2) Information needs related to before pregnancy including physical health, mental readiness, factors that affect fetus health, screening for genetic disease, and screening for mother disease (in this section the information needs had to be prioritized from 1 to 3); 3) Information needs during pregnant such as psychosocial issues, physical problems, mental disorders, common problems, limitations, vaccination and prenatal care (in this section the information needs had to be prioritized from 1 to 4 ). Then, the primary questionnaire was reviewed for content validity (through the content validity index (CVI)), and then evaluated by 10 experts in Obstetrics and Gynecology and health information management area, who offered feedback in relation to the simplicity and clarity of questions, and the relationship between questions. The experts evaluated each question on a 4-point scale ( $1=$ low score; $4=$ high score), and the ratio of their response scores ( 3 and 4 to the total of 10 responses) were obtained. Items with scores higher than 0.80 were considered suitable; items with scores of less than 0.80 were removed or revised as recommended by the experts. Next, the questionnaire was rewritten and became more focused as a result of the experts' suggestions. Then we piloted the questionnaire on thirty pregnant women randomly selected from different health care centers. Participants in the pilot study were excluded from the study. Internal consistency was expressed as Cronbach's alpha 0.932 for the second section of the questionnaire. Next, further revisions were made and some statements were rephrased. Lastly, the final version of the anonymous questionnaire was distributed among the participants and they were asked to complete the questionnaire.

\subsection{Data Analysis}

To determine the distributions of responses, SPSS16 was used to perform descriptive statistics. The mean and standard deviation for each item was reported.

\subsection{Ethical Consideration}

First, we obtained ethical approval from the Semnan University of Medical Ethics Committee. Then, we prepared a cover letter describing the purposes of the study. The letter explained that responding to the survey indicated the participants' consent to take part in the research. It also assured the participants that all responses would be kept confidential. 


\section{Results}

The results indicated that $40.0 \%(n=80)$ were 25 - 30 years old. (Table 1$) 42.5 \%(n=85)$ had a gestational age less than eight weeks, 53\% $(n=106)$ were experiencing their first pregnancy,76.5\% $(n=153)$ had not previous abortion. (Table 2) In connection with the participants' preferences to receive information before pregnancy, the results showed that $17.5 \%(n=35)$ information about physical health to become pregnant, $36 \%(n=72)$ psychological readiness for pregnancy, $46.5 \%(n=93)$ factors that affect fetal health, $71 \%(n=142)$ screening for genetic diseases and $29 \%(n=58)$ screening for mother's illnesses reported as the first priority of their preferences. (Table 3 ). In connection with the participants' preferences to receive information during pregnancy, the results showed that $12 \%$ $(\mathrm{n}=24)$ information about smoking and its impact on the health of the fetus, 57.5\% $(n=115)$ domestic violence and its impact on the health of the mother and fetus, 31\% ( $n=$ 62 ) consumption of illegal drugs, $11.5 \%(n=23)$ tooth care during pregnancy, 57\% $(\mathrm{n}=114)$ changes in body in pregnancy, 9.5\% $(n=19)$ number of meals per day, $23 \%(n=46)$ food consumption per meal, 39.5\% $(n=79)$ vitamins and minerals needed during pregnancy, $28.5 \%(n=57)$ food intake effecting the baby's intelligence and beauty. $27 \%$ $(\mathrm{n}=54)$ depression in pregnancy, 62.5\% $(\mathrm{n}=125)$ anxiety and coping styles with it in pregnancy, 10.5\% $(n=21)$ sleep disorders in pregnancy, 39\% $(\mathrm{n}=78)$ nausea and vomiting in pregnancy, $29 \%(\mathrm{n}=58)$ about low back pain, $31.5(\mathrm{n}=$ 63) about sports activities, 50.5\% $(n=101)$ sexual activity during pregnancy, $18 \%(\mathrm{n}=36)$ about going to travel in pregnancy, $17.5 \%(\mathrm{n}=35)$ authorized vaccines in pregnancy, $14.5 \%(\mathrm{n}=29)$ cares that should be provided per visit reported as the first priority of pregnant women's preferences (Table 4). Number of previous delivery had a negative and significant relationship with the pregnant women's preferences ( $\mathrm{B}=-1.31, \mathrm{P}<0.001$ ) (Table 5).

\begin{tabular}{lc}
\hline \multicolumn{2}{l}{ Table 1. Demographic Characteristics ${ }^{\mathrm{a}}$} \\
\hline Characteristics & Values \\
\hline Age, $\mathbf{y}$ & \\
$<20$ & $12(6)$ \\
$20-25$ & $60(30)$ \\
$25-30$ & $80(40)$ \\
\hline $30-35$ & $26(13)$ \\
\hline 35 & $11(5.5)$ \\
\hline Missing & $11(5.5)$ \\
\hline Job & \\
\hline Employee & $23(11.5)$ \\
\hline Teacher & $10(5.0)$ \\
\hline Housekeeper & $155(77.5)$ \\
\hline Other & $12(6.0)$ \\
\hline Education level & $19(9.5)$ \\
\hline Uneducated & $96(48)$ \\
\hline Diploma & $73(36.5)$ \\
\hline Bachelor degree & \\
\hline
\end{tabular}

\begin{tabular}{|cc|}
\hline Master degree & $11(5.5)$ \\
\hline Missing & $1(0.5)$ \\
\hline Habitat & $194(97.0)$ \\
\hline City & $6(3.0)$ \\
\hline Village & \\
\hline Income level & $8(4.0)$ \\
\hline Low & $182(91.0)$ \\
\hline Average & $10(5.0)$ \\
\hline High & \\
\hline Husband occupation & $44(22)$ \\
\hline Employee & $4(2)$ \\
\hline Teacher & $6(3)$ \\
\hline Engineer & $37(18.5)$ \\
\hline Worker & $74(37)$ \\
\hline Other & $1(0.5)$ \\
\hline Workless & $34(17.0)$ \\
\hline Missing & \\
\hline Spouse's Education & $35(17.5)$ \\
\hline Uneducated & $101(50.5)$ \\
\hline Diploma & $42(21.0)$ \\
\hline Bachelor degree & $21(10.5)$ \\
\hline Master degree & $1(0.5)$ \\
\hline Missing & \\
\hline Data are presented as No.(\%). & \\
\hline
\end{tabular}

Table 2. The Participants' Medical History ${ }^{\mathrm{a}}$

\begin{tabular}{|cc}
\hline Characteristics & Values \\
\hline Gestational age, $\mathbf{w}$ & \\
$<8$ & $85(42.5)$ \\
\hline $8-16$ & $9(4.5)$ \\
\hline $16-24$ & $29(14.5)$ \\
\hline $24-32$ & $35(17.5)$ \\
\hline$>32$ & $37(18.5)$ \\
\hline Missing & $5(2.5)$ \\
\hline Previous delivery numbers & \\
\hline 0 & $106(53.0)$ \\
\hline 1 & $75(37.5)$ \\
\hline 2 & $17(8.5)$ \\
\hline 3 & $2(1.0)$ \\
\hline Abortion & \\
\hline 0 & $153(76.5)$ \\
\hline 1 & $33(16.5)$ \\
\hline 2 & $7(3.5)$ \\
\hline 3 & $7(3.5)$ \\
\hline Number of living children & \\
\hline 0 & $104(52.0)$ \\
\hline 1 & $76(38.0)$ \\
\hline 2 & $18(19.0)$ \\
\hline 3 & $2(1.0)$ \\
\hline Family relationship with & \\
\hline spouse & \\
\hline Yes & $58(29.0)$ \\
\hline No & \\
\hline
\end{tabular}


Kahouei M et al.

\begin{tabular}{lccc}
\hline \multicolumn{2}{l}{\begin{tabular}{l} 
Table 3. Prioritizing of Women's Health Information Needs About Before Pregnancy \\
\hline Information Needs
\end{tabular}} & \multicolumn{1}{c}{ Priorities } \\
\cline { 2 - 4 } & First & Second & Third \\
\hline Physical health to become pregnancy & $35(17.5)$ & $86(43.0)$ & $79(39.5)$ \\
Mental readiness for pregnancy & $72(36.0)$ & $60(30.0)$ & $68(34.0)$ \\
Factors that affect fetus health & $93(46.5)$ & $54(27.0)$ & $53(26.5)$ \\
Screening for genetic disease & $142(71.0)$ & $58(29.0)$ & 0 \\
\hline Screening for mother disease & $58(29.0)$ & $142(71.0)$ & 0 \\
\hline
\end{tabular}

${ }^{\mathrm{a}}$ Data are presented as No. (\%).

Table 4. Prioritizing of Women's Health Information Needs During Pregnancy ${ }^{\mathrm{a}}$

\begin{tabular}{|c|c|c|c|c|}
\hline \multirow[t]{2}{*}{ Information Need } & \multicolumn{4}{|c|}{ Priorities } \\
\hline & First & Second & Third & Fourth \\
\hline \multicolumn{5}{|l|}{ Psychosocial issues } \\
\hline Smoking and its impact on the health of fetus & $24(12.0)$ & $55(27.5)$ & $121(60.5)$ & 0 \\
\hline Domestic violence and its impact on the health of mother and fetus & $115(57.5)$ & $60(30.0)$ & $25(12.5)$ & 0 \\
\hline The use of illegal drugs & $62(31.0)$ & $84(42.0)$ & $54(27.0)$ & 0 \\
\hline \multicolumn{5}{|l|}{ Physical issues } \\
\hline Appropriate weight & $62(31.0)$ & $82(41.0)$ & $56(28.0)$ & 0 \\
\hline Dental care & $23(11.5)$ & $66(33.0)$ & $111(55.5)$ & 0 \\
\hline Change in body systems & $114(57.0)$ & $52(26.0)$ & $34(17.0)$ & 0 \\
\hline \multicolumn{5}{|l|}{ Nutrition } \\
\hline The number meals & $19(9.5)$ & $20(10.0)$ & $43(21.5)$ & $118(59.0)$ \\
\hline Food consumption per meal & $46(23.0)$ & $52(26.0)$ & $85(42.5)$ & $17(8.5)$ \\
\hline Vitamins and minerals that are needed & $79(39.5)$ & $83(41.5)$ & $26(13.0)$ & $12(6.0)$ \\
\hline food intake effecting the baby's intelligence and beauty & $57(28.5)$ & $48(24.0)$ & $47(23.5)$ & $48(24.0)$ \\
\hline \multicolumn{5}{|l|}{ Mental disorders } \\
\hline Depression & $54(27.0)$ & $82(41.0)$ & $64(32.0)$ & 0 \\
\hline Anxiety and coping styles with it & $125(62.5)$ & $52(26.0)$ & $23(11.5)$ & 0 \\
\hline \multicolumn{5}{|l|}{ Prevalent problems } \\
\hline Sleep Disorders & $21(10.5)$ & $65(32.5)$ & $114(57.0)$ & 0 \\
\hline Nausea and vomiting & $78(39.0)$ & $45(22.5)$ & $47(23,5)$ & $30(15.0)$ \\
\hline Low back pain & $58(29.0)$ & $58(29.0)$ & $53(26.5)$ & $31(15.5)$ \\
\hline \multicolumn{5}{|l|}{ Limitations } \\
\hline Sports activities & $63(31.5)$ & $68(34.0)$ & $69(34.5)$ & 0 \\
\hline Sexual activities & $101(50.5)$ & $54(27.0)$ & $45(22.5)$ & 0 \\
\hline Going to travel & $36(18.0)$ & $78(39.0)$ & $86(43.0)$ & 0 \\
\hline \multicolumn{5}{|l|}{ Vaccination } \\
\hline Authorized vaccines & $35(17.5)$ & $66(33.0)$ & $99(49.5)$ & 0 \\
\hline \multicolumn{5}{|l|}{ Referrals } \\
\hline Time the first visit & $61(30.5)$ & $35(17.5)$ & $53(26.5)$ & $51(25.5)$ \\
\hline Time the next visit & $8(4.0)$ & $32(16.0)$ & $68(34.0)$ & $92(46.0)$ \\
\hline Dangerous signs that need to refer & $103(52)$ & $51(25)$ & $24(12)$ & $22(11)$ \\
\hline
\end{tabular}

${ }^{\mathrm{a}}$ Data are presented as No. (\%). 
Kahouei M et al.

Table 5. Stepwise Regression Factors Influencing the Pregnant Women's Preferences

\begin{tabular}{lccccc}
\hline Demographic characteristic & $\mathbf{R}$ & $\mathbf{R}^{2}$ & $\mathbf{B}$ & $\mathbf{t}$ & P-Value \\
\hline Number of previous delivery & .892 & .796 & -1.31 & -27.781 & $<0.001$ \\
\hline
\end{tabular}

\section{Discussion}

This study was done with an aim of prioritizing women's information needs in receiving health information on the time before and during pregnancy. It shows that receiving information in the field of factors affecting on fetus health is the first priority of information needs of some women in preconception period. The results of Chen et al. s' study confirm the finding of the study. They found that awareness of the health of fetus was one of the main concerns, and worries of pregnant women (19). The results of the present study suggests the tendency of women to receive information about risk factors affecting health of the fetus that can be effective on diagnosing, treating and preventing non-compensated injuries (20).

The findings of this study show that few women concern receiving information about mother diseases screening, and having physical health for pregnancy. The results indicate that our society women are oblivious to their health for getting pregnant and do not feel the need to receive information about it. So an attempt to notify them of this field seems necessary.

The findings of this study indicate that first preference of more than one-third of women were receiving information about mental preparation to become pregnant in pre-pregnancy stage. It indicates that some women experience symptoms of depression in reproductive age, and this makes them worried about complications due to mental problems in pregnancy period, and their impact on pregnancy outcome.

The findings of the study show the importance of providing information to women in reproductive age in relation to importance of preconception cares, because of having a great role in the identification of risk factors, especially mother physical diseases, and on-time intervention and pregnancy outcome improvement is essential (21).

The results showed less population preferred during pregnancy first to receive information about smoking and illegal drugs, and its impact on the health of the fetus. Despite smoking is increasing sharply among women in developing countries, and in Iran $7 \%$ of pregnant women smoke and $29.3 \%$ of them are passive smokers, or secondhand-smokers (22); the results showed that most Iranian pregnant women do not consider smoking harms during their pregnancy, that increase incidence probability of congenital neurological abnormalities of newborns, gestational diabetes, and postpartum hemorrhage, and even passive smoking of a mother increases the risk of low weight birth $(23,24)$, perhaps less tendency of Iranian pregnant women to obtain information on smoking in terms of culture is not accepted. Hence, it seems that lack of information for Iranian pregnant women is not considered as a health threatening problem among pregnant women.

Given that maternal appropriate weight gain during pregnancy is very impressive on fetal growth (25), but, the findings of this study showed that only about a onethird of study subjects asked for receiving information about this. The findings could indicate that some women experienced the effect of improper weight gain on lowweight newborn birth. Given proper nutrition during pregnancy is an important factor in maternal weight and fetal growth, and birth weight (26), but, in this study a few of the population first asked for receiving information on the number of meals. The results showed that many women do not consider the importance of the effect of appropriate nutrition and weight during pregnancy on newborn health. While the findings show that some pregnant women first prefer to receive information about needed vitamins and minerals that should be consumed in the form of supplementary, and food that influence on intelligence and beauty of the newborn. It seems some mothers concern more about infant intelligence and beauty and do not consider their health. So, the findings of this study also suggest that pregnant women do not concern receiving information about how to take oral care. Other studies have also shown that pregnant women's awareness in the field of oral care is very partial (27-29).

The findings of this study show that in relation to physical problems, pregnant women group first prefers to receive information about changes in body systems. The results could imply that most women have experienced some physical changes, such as, restless legs syndrome and mood changes that are usually associated to it (30) and these changes are tangible and sometimes problematic for them and likely to increase their concerns. Therefore, they express even more feeling about information receiving on this field.

The findings of this study suggest that in relation to psychological disorders, there are many pregnant women who first prefer to receive information about pregnancy anxiety, and the styles of dealing with it. Other studies have also showed that pregnant women suffer from varying degrees of depression and from anxiety disorders $(31,32)$. It seems unknown fear, stress, and daily activities pressure make them feel more to receive such information. Further, physical, psychological, and emotional changes during pregnancy prepare the ground for family disputes and violence (33). The results showed that receiving information about domestic violence was of primary preference of more than half of pregnant women. 
Further, domestic violence is a hidden and persistent epidemic among women (34) that many women experience violence before and during pregnancy. Jahanfar et al. s' study showed that the prevalence of domestic violence among Iranian pregnant women was > 60\% (35). Regarding intangible nature of the issue to women, the study again shows stress and anxiety management importance during pregnancy and routine screening of domestic violence in care program of before and during pregnancy, as a main measure to reduce its impact on the health of the mother and fetus.

The study findings also indicate that receiving information about sleep disorders can be of first priority of information needs of pregnant women. Some pregnant women also experienced psychological disorders, following sleep disorders. Studies have shown that there is a correlation between sleep pattern disorder with depression during pregnancy, and also postpartum depression; and the depression endangers the health of the mother and fetus (36-39).

The study findings indicate that receiving information about nausea, vomiting and low back pain for some pregnant women is of particular importance. It seems that these common problems during pregnancy endanger mental health and social functions of some women and cause their low quality of life.

The study findings suggest the need for receiving information about exercise during pregnancy cannot be too much considered by pregnant women. These results suggest that possibly some pregnant women have not experienced benefits of sports activities during pregnancy, such as, easier childbirth and reducing maternal complications (40), or are not aware of it. So, Rahimi and SeyyedRasooli found that the knowledge of Iranian women of exercise during pregnancy was partial (41). Further, the reason for the lack of a great need for this type of information may be due to women's gestational age, because studies have shown that by gestational age development, physical activities, such as, exercise are decreased (42-44). With regard to limitations, the results suggest that pregnant women group prefers first to receive information about sexual activities during pregnancy. Perhaps given the effects of physiological, anatomical, and psychological changes during pregnancy on reducing sexual activity, and lack of awareness of this condition that can have negative effects on relations between spouses and disturb family mental health (45) would eventually lead to make pregnant women more sensitive about receiving information about sexual activity. Heydari et al. study also showed that about $60 \%$ of men and $70 \%$ women in Iran are unaware about sexual relations during pregnancy (46).

The findings of this study suggest the need for information receiving about travelling during pregnancy cannot be considered more by pregnant women. Although traveling does not make a risk, or problem for pregnancy, but the findings suggest that possibly most pregnant women do not find out the importance of consulting a doctor before traveling. The study of Jean et al. also showed that pregnant women awareness about a safe travel during pregnancy was partial (47).

The results of this study suggest that in relation to vaccination, some pregnant women prefer first to receive information about the vaccines that should be received during pregnancy, and the vaccines that are prohibited. Mojahed et al. s' study showed that one of the greatest causes of non-injection of tetanus vaccine among Iranian pregnant women in Iran has been a lack of awareness of the need for vaccination (48). The results indicate that awareness of the importance of immunization that is one of important parts of health care of pregnant women, is one of the first priority of preferences of some pregnant women.

The results of this study indicate that the need for receiving information about care in pregnancy period can be the first priority of a limited number of pregnant women. These results are probably the most Iranian pregnant women receive average and inadequate pregnancy period cares (49), and some factors that are barriers for receiving the cares are the lack of need for the cares by women, and their lack of knowledge of the numbers and how to refer to health centers properly (50). Regression analysis showed among the pregnant women's characteristics, number of previous delivery only factor influencing women's preferences. So that women who had more previous delivery, their need this information to be lower.

\subsection{Implications}

The results of this study have several implications. Firstly, the results showed that pregnant women put different information needs in first priority. This could possibly indicate that information needs of individuals based on their unique characteristics, such as, gestational age, or birth history are different from each different. So, pregnant women with older gestational age and a history of previous childbirth may have already received some information, and their information need is different from pregnant women with younger gestational age and with the first pregnancy. Also, studies have shown that the age and health status are the two main factors that influence people's information needs.

Secondly, the results of this study suggest that pregnant women in a developing country are concerned about the problems during pregnancy period and that they are unaware of issues, so that the findings suggest that many pregnant women prefer their baby's health to their health. They concern more intelligence and beauty of their babies than their health. This could represent the culture and their quality of life during pregnancy period.

Thirdly, the results showed that most of pregnant women were housewives and with diploma level. This fact indicates the importance of effective providing high- 
quality information for pregnant women. So informative support for this pregnant women group leads mothers go through this important stage of life more pleasant, and with fewer complications, and prepare them for an easier natural childbirth and thereby improve their quality of life. Also providing information to this group of the population leads them to feel they are being supported.

\subsection{Limitations and Future Researches}

The results of this study should be interpreted with caution because the study was conducted using a researcher made questionnaire survey method and potential problems, such as, poor understanding of questions and probably bias answer threaten the results of the study, that is resolved with regard to questionnaire validity and reliability. Also, non-generalizable results of the study because of being done in a city, is of the other limitations of this study. But, however, the study results were in line with other studies in this field. Further, quantitative nature of this study limits the study capacity, so one cannot discover pregnant women experiences for his/her information needs. Also, further studies should be performed to determine whether unsatisfied information needs increase stress and anxiety of pregnant women during pregnancy and thereafter. Also, what the most-effective methods are providing information to women, and that how women can be supported in relation to their information needs.

\subsection{Conclusion}

The findings of the study showed that in a developing country, pregnant women feel the lack of what kind of information before and during pregnancy, i.e., the findings of this study indicate unsatisfied learning needs, and the information perceived importance for pregnant women. This study shows that in preconception period and in pregnancy period in areas of social, physical, psychological issues, common problems, limitations, vaccination, and pregnancy period cares, pregnant women put different information needs in their first priority. Providing complete, accurate, and timely information to women based on their real needs, especially in preconception period helps health care providers in these countries to change healthy mother-healthy child model to healthy woman-healthy mother - healthy child model more simply.

\section{Acknowledgments}

The authors wish to acknowledge the pregnancy women's contributions. We would like to thank the clinical research development unit of Amiralmomenin Educational, research and therapeutic centers of Semnan Uiversity of Medical Sciences for providing facilities to this work.

\section{Footnote}

Authors' Contribution:Mehdi Kahouei prepared grant submissions for the project; Mehri Ansari Niaki was involved in the planning, preparation and approval of the original questionnaire. Golnar Homayoon and Somayeh Sadat Razavi conducted the questionnaire survey and data collection. All authors contributed to the writing of the article, and read and approved the final manuscript.

\section{References}

1. Kahouei M, Askari Majdabadi H, Karimi M, Ghazavi Shariat Panahi SS, Ali Akbari S, Kazemzadeh F, et al. Nurses' perception about the effect of hospital information system in Iran. Int Inf Inst. 2012;15(4):1823.

2. Kahouei M, Mehri F, Panoe SR, Zeinab P, Alaei S, Majid A. Evidencebased information resources management skill among Iranian residents, internship and nursing students in urgent care. Sci Res Essays. 2011;6(22):4708-13.

3. Jedlitschka A, Juristo N, Rombach D. Reporting experiments to satisfy professionals' information needs. Empiric Software Engin. 2013;19(6):1921-55. doi:10.1007/s10664-013-9268-6.

4. Kahouei M, Alaei S, Panahi SS, Zadeh JM. The assessment of strategic plans of a developing country for solving barriers to access evidence-based information sources. J Evid Based Med. 2014;7(1):45-51. doi: 10.1111/jebm.12086. [PubMed: 25155566]

5. Koblinsky M, Tain F, Tesfaye S. Reducing maternal mortality and increasing use of skilled birth attendance: Ethiopia and MDG 5. Ethiopia J Reprod Health. 2010;4(1):4-15.

6. De Allegri M, Ridde V, Louis VR, Sarker M, Tiendrebeogo J, Ye $M$, et al. Determinants of utilisation of maternal care services after the reduction of user fees: a case study from rural Burkina Faso. Health Policy. 2011;99(3):210-8. doi: 10.1016/j.healthpol.2010.10.010. [PubMed: 21056505]

7. Davari Tanha F, Ghajarzadeh M, Mohseni M, Shariat M, Ranjbar M. Is ACOG guideline helpful for encouraging pregnant women to do exercise during pregnancy? Acta Med Iran. 2014;52(6):45861. [PubMed: 25130154]

8. Javadian P, Alimohamadi S, Gharedaghi MH, Hantoushzadeh S. Gestational diabetes mellitus and iron supplement; effects on pregnancy outcome. Acta Med Iran. 2014;52(5):385-9. [PubMed: 24902020]

9. Elsinga J, de Jong-Potjer LC, van der Pal-de Bruin KM, le Cessie S, Assendelft WJ, Buitendijk SE. The effect of preconception counselling on lifestyle and other behaviour before and during pregnancy. Womens Health Issues. 2008;18(6 Suppl):S117-25. doi: 10.1016/j.whi.2008.09.003. [PubMed:19059545]

10. Frey KA, Files JA. Preconception healthcare: what women know and believe. Matern Child Health J. 2006;10(5 Suppl):S73-7. doi: 10.1007/s10995-006-0110-2. [PubMed:16775757]

11. D'Ambruoso L, Abbey M, Hussein J. Please understand when I cry out in pain: women's accounts of maternity services during labour and delivery in Ghana. BMC Public Health. 2005;5:140. doi: 10.1186/1471-2458-5-140. [PubMed:16372911]

12. Lee NM, Saha S. Nausea and vomiting of pregnancy. Gastroenterol Clin North Am. 2011;40(2):309-34. doi: 10.1016/j.gtc.2011.03.009. [PubMed: 21601782]

13. Dunkel Schetter C, Tanner L. Anxiety, depression and stress in pregnancy: implications for mothers, children, research, and practice. Curr Opin Psychiatry. 2012;25(2):141-8. doi: 10.1097| YCO.0b013e3283503680. [PubMed: 22262028]

14. Moshki M, Bahri N, Sadegh Moghaddam L. Study of lifestyles among pregnant women Gonabad. J Specialized Res Health. 2012;2(2):18-29.

15. Grimes HA, Forster DA, Newton MS. Sources of information used by women during pregnancy to meet their information needs. Midwifery. 2014;30(1):e26-33. doi: 10.1016/j.midw.2013.10.007. [PubMed: 24246969]

16. Uchudi JM. Covariates of child mortality in Mali: does the health-seeking behaviour of the mother matter? J Biosoc Sci. 2001;33(1):33-54. [PubMed:11316394]

17. Fatmi Z, Avan BI. Demographic, socio-economic and environmental determinants of utilisation of antenatal care in a rural 
setting of Sindh, Pakistan. J Pak Med Assoc, 2002;52(4):138-42. [PubMed: 12174476]

18. Golparvar M, Bahadoran P, Rizi H.The role of Components of group cohesion in the tendency of pregnant women to participate in the physical fitness periods. J Reprod Infertil. 2011;12(2):145-55.

19. Chen $\mathrm{CH}$, Chen HM, Huang TH. Stressors associated with pregnancy as perceived by pregnant women during three trimesters. Gaoxiong Yi Xue Ke Xue Za Zhi.1989;5(9):505-9. [PubMed:2607562]

20. Haas JS, Jackson RA, Fuentes-Afflick E, Stewart AL, Dean ML, Brawarsky P, et al. Changes in the health status of women during and after pregnancy. J Gen Intern Med. 2005;20(1):45-51. doi: 10.1111/j.1525-1497.2004.40097.x. [PubMed:15693927]

21. Floyd RL, Johnson KA, Owens JR, Verbiest S, Moore CA, Boyle C. A national action plan for promoting preconception health and health care in the United States (2012-2014). J Womens Health (Larchmt). 2013;22(10):797-802. doi: 10.1089/jwh.2013.4505. [PubMed: 23944970]

22. Mojibyan M, Karimi M, Bidaki R, Rafiee P, Zare A. Exposure to Second-hand Smoke During Pregnancy and Preterm Delivery. Int J High Risk Behav Addict. 2013;1(4):149-53. doi: 10.5812/ijhrba.7630. [PubMed: 24971254]

23. Jamshidi Ardeshiri M, Moosazadeh M, Feizi Masouleh M, Feiz Masouleh M, Kiani A, Fakhri M. Prevalence of smoking in 15-64 years old population of north of Iran: meta-analysis of the results of non-communicable diseases risk factors surveillance system. Acta Med Iran. 2013;51(7):494-500. [PubMed:23945896]

24. Talati A, Bao Y, Kaufman J, Shen L, Schaefer CA, Brown AS. Maternal smoking during pregnancy and bipolar disorder in offspring. Am J Psychiatry. 2013;170(10):1178-85. doi: 10.1176/appi ajp.2013.12121500. [PubMed: 24084820]

25. Royall D. Evaluating Diet during Pregnancy. Can J Diet Pract Res. 2011;72(2):56. doi: 10.3148/72.2.2011.56.

26. Sen S, Carpenter AH, Hochstadt J, Huddleston JY, Kustanovich $\mathrm{V}$, Reynolds AA, et al. Nutrition, weight gain and eating behavior in pregnancy: a review of experimental evidence for longterm effects on the risk of obesity in offspring. Physiol Behav. 2012;107(1):138-45. doi: 10.1016/j.physbeh.2012.04.014. [PubMed 22546810]

27. Corbella S, Taschieri S, Del Fabbro M, Francetti L, Weinstein R, Ferrazzi E. Adverse pregnancy outcomes and periodontitis: A systematic review and meta-analysis exploring potential association. Quintessence Int. 2015. doi:10.3290/j.qi.a34980. [PubMed: 26504910]

28. Offenbacher S, Beck JD, Jared HL, Mauriello SM, Mendoza LC, Couper DJ, et al. Effects of periodontal therapy on rate of preterm delivery: a randomized controlled trial. Obstet Gynecol. 2009;114(3):551-9. doi: 10.1097|AOG.ob013e3181b1341f. [PubMed: 19701034]

29. Corbella S, Taschieri S, Francetti L, De Siena F, Del Fabbro M. Periodontal disease as a risk factor for adverse pregnancy outcomes: a systematic review and meta-analysis of case-control studies. Odontology. 2012;100(2):232-40. doi: 10.1007/s10266-011-0036-Z. [PubMed: 21739194]

30. Shimizu H, Sono Y, Ohtake N, Nishioka H. Restless Legs Syndrome with Severe Limb Pain during Pregnancy. General Med. 2014;15(1):52-5. doi:10.14442/general.15.52.

31. Bunevicius A, Cesnaite E. Antenatal maternal mental state and anthropometric characteristics of the neonates: impact of symptoms of depression and anxiety. Biologin Psichiatrija. 2007:3-6.

32. Neggers Y, Goldenberg R, Cliver S, Hauth J. The relationship between psychosocial profile, health practices, and pregnancy outcomes. Acta Obstet Gynecol Scand. 2006;85(3):277-85. [PubMed 16553174]

33. Das S, Bapat U, Shah More N, Alcock G, Joshi W, Pantvaidya S, et al. Intimate partner violence against women during and after pregnancy: a cross-sectional study in Mumbai slums. BMC Public Health. 2013;13:817. doi: 10.1186/1471-2458-13-817. [PubMed:
24015762

34. Roelens K, Verstraelen H, Van Egmond K, Temmerman M. Disclosure and health-seeking behaviour following intimate partner violence before and during pregnancy in Flanders, Belgium: a survey surveillance study. Eur J Obstet Gynecol Reprod Biol. 2008;137(1):37-42. doi: 10.1016/j.ejogrb.2007.04.013. [PubMed: 17544199]

35. Jahanfar S, Malekzadegan Z. The prevalence of domestic violence among pregnant women who were attended in Iran University of Medical Science Hospitals. J Fam Violence. 2007;22(8):643-8.

36. Balendran J, Champion D, Jaaniste T, Welsh A. A common sleep disorder in pregnancy: restless legs syndrome and its predictors. Aust N Z J Obstet Gynaecol. 2011;51(3):262-4. doi: 10.1111/j.1479828X.2011.01294.x. [PubMed: 21631448

37. Field T, Diego M, Hernandez-Reif M, Figueiredo B, Schanberg S, Kuhn C. Sleep disturbances in depressed pregnant women and their newborns. Infant Behav Dev. 2007;30(1):127-33. doi:10.1016/j. infbeh.2006.08.002. [PubMed:17292785]

38. Skouteris H, Germano C, Wertheim EH, Paxton SJ, Milgrom J. Sleep quality and depression during pregnancy: a prospective study. Sleep Res. 2008;17(2):217-20. doi: 10.1111/j.1365-2869.2008.00655.x. [PubMed: 18482110$]$

39. Kamysheva E, Skouteris H, Wertheim EH, Paxton SJ, Milgrom J. A prospective investigation of the relationships among sleep quality, physical symptoms, and depressive symptoms during pregnancy. J Affect Disord. 2010;123(1-3):317-20. doi: 10.1016/j. jad.2009.09.015. [PubMed:19822370]

40. Nascimento SL, Surita FG, Cecatti JG. Physical exercise during pregnancy: a systematic review. Curr Opin Obstet Gynecol. 2012;24(6):387-94. doi: 10.1097/GCO.0b013e328359f131. [PubMed 23014142]

41. Rahimi S, SeyyedRasooli A. Pregnant women and exercise. Iran J Nurs. 2005;17(40):6-10.

42. Gardner B, Wardle J, Poston L, Croker H. Changing diet and physical activity to reduce gestational weight gain: a meta-analysis. Obes Rev. 2011;12(7):e602-20. doi: 10.1111/j.1467-789X.2011.00884.X. [PubMed: 21521451]

43. Tobias DK, Zhang C, van Dam RM, Bowers K, Hu FB. Physical activity before and during pregnancy and risk of gestational diabetes mellitus: a meta-analysis. Diabetes Care. 2011;34(1):223-9. doi: 10.2337/dc10-1368. [PubMed: 20876206]

44. Russo LM, Nobles C, Ertel KA, Chasan-Taber L, Whitcomb BW. Physical activity interventions in pregnancy and risk of gestational diabetes mellitus: a systematic review and metaanalysis. Obstet Gynecol. 2015;125(3):576-82. doi: 10.1097| AOG.0000000000000691. [PubMed:25730218]

45. Serati M, Salvatore S, Siesto G, Cattoni E, Zanirato M, Khullar $\mathrm{V}$, et al. Female sexual function during pregnancy and af ter childbirth. J Sex Med. 2010;7(8):2782-90. doi: 10.1111/j.1743 6109.2010.01893.x. [PubMed:20626601]

46. Heydari M. Couples' knowledge and attitude about sexuality in pregnancy. Tehran Univ Med J. 2006;64(9):83-9.

47. Jean D, Moore LG. Travel to high altitude during pregnancy: frequently asked questions and recommendations for clinicians. High Alt Med Biol. 2012;13(2):73-81. doi: 10.1089/ham.2012.1021. [PubMed: 22724609]

48. Mojahed S, Zare F, Bokaei M, Anjazab B. The study of tetanus vaccination among pregnant women referring to labor centers in Yazd. J Shahid Sadooghi Yazd Univ Med Sci. 2005;13(3):67-74.

49. Khanjari S, Molla F, Hosseini F, Faragollahi M. Prenatal care utilization and factors affecting to receive prenatal care from clients perspectives. Iran J Nurs. 2006;19(45):37-48.

50. Callaway LK, Colditz PB, Byrne NM, Lingwood BE, Rowlands If, Foxcroft K, et al. Prevention of gestational diabetes: feasibility issues for an exercise intervention in obese pregnant women. Diabetes Care. 2010;33(7):1457-9. doi:10.2337/dc09-2336. [PubMed 20357374 